\title{
¿Puede hablar el traductor? Nuevos abordajes para la traducción de literatura afrodescendiente en Brasil bajo la óptica de los Estudios Culturales*
}

\author{
Liliam Ramos da Silva ${ }^{1}$ \\ Universidade Federal do Rio Grande do Sul (Brasil)
}

\section{Resumen}

Este texto tiene como objetivo analizar la carga semántica de los términos "esclavo/a" y "mulato/a" en el contexto brasileño y propone una discusión sobre la resignificación de su sentido bajo la óptica de los Estudios Culturales. Los teóricos de los Estudios Culturales utilizados en el ensayo -Gayatri Spivak, Stuart Hall y Boaventura Sousa Santossostienen que el sujeto poscolonial se ubica entre dos culturas y constantemente desarrolla estrategias de traducción cultural entre diferentes pueblos. Las investigadoras de los Estudios de la Traducción Susan Bassnet y Rosemary Arrojo incluyen los textos traducidos en una perspectiva intercultural, en la que

\section{Abstract}

The aimed to analyze the semantic content of the terms slave and mulatto within the Brazilian context, thus proposing a discussion about the resignification of their meaning from the perspective of Cultural Studies. Gayatri Spivak, Stuart Hall and Boaventura Sousa Santos, who compose the theoretical background of Cultural Studies in this essay, presuppose that the postcolonial individual is someone who stands between two cultures and is constantly developing cultural translation strategies among different peoples. Susan Bassnet and Rosemary Arrojo, researchers of the Translation Studies field, include translated texts in an intercultural perspective, in which the

\footnotetext{
* Can the translator speak? New approaches to translation of African-Brazillian literature in the light of the Cultural Studies.

1 Doctora en Letras. Docente en la Universidad Federal de Río Grande del Sur (UFRGS, Brasil). Profesora de las asignaturas de Tradução y Versão do Espanhol en la carrera de Letras/Traducción del Instituto de Letras de la UFRGS. Entre el 2014 y 2016 coordinó el proyecto "Tradução e Legendagem na UFRGS". Desde el 2012 coordina el proyecto Vozes negras no romance hispano-americano. e-mail: liliam. ramos@ufrgs.br
} 
el traductor no puede eximirse; tampoco invisibilizarse. Salgueiro y Carrascosa discuten la traducción afrodiaspórica en el contexto brasileño. Se debatirá el rol del traductor que transcodifica textos incluidos en la perspectiva poscolonial y su mediación en la traducción lingüística y cultural.

Palabras clave: Estudios de Traducción, Estudios Culturales, esclavitud en América Latina, esclavo/a, mulato/a. translator cannot escape or be invisible. Salgueiro and Carrascosa argue the Afro-diasporic translation in the Brazilian context. The essay presents discussions concerning the role of the translator who transcodes texts included in the postcolonial perspective and their mediation in linguistic and cultural translation.

Keywords: Translation Studies, Cultural Studies, Slavery in Latin America, Slave, Mulatto.

\section{Preliminares}

La traducción es un proceso intercultural cuyo resultado permite analizar la manera como una determinada sociedad recibe una obra, un/a autor/a, una literatura, una cultura diferente de la suya. Las diversas reflexiones sobre traducción (y sus prácticas, abordajes teóricos, recepción), que tuvieron como consecuencia la constitución de los Estudios de la Traducción como una asignatura independiente, se han consolidado para pensar la traducción más allá de la transposición semiótica con foco en los procesos lingüísticos. El acto de traducir involucra un conjunto complejo de criterios extralingüísticos que se profundizan en una dimensión cultural mucho más abarcadora: el traductor asume un rol que traspasa el de mediador lingüístico, constituyéndose también en mediador cultural entre textos y culturas distintas.

Tomando prestado el título del ensayo “¿Puede hablar el subalterno?" (1988) ${ }^{2}$, de la intelectual india Gayatri Spivak -en el cual la especialista en crítica literaria cuestiona la real apertura de espacio para las voces de los individuos cuyas culturas y representaciones son consideradas subalternas, y que conviven con la opresión y el silenciamiento en contextos patriarcales y poscoloniales-, pretendemos plantear cómo la participación del traductor en las obras incluidas en la perspectiva poscolonial

\footnotetext{
${ }^{2}$ Utilizaremos como referencia la traducción del número 39 de la Revista Colombiana de Antropología (2003).
} 
será determinante en la (re)producción de un texto que necesita transponer a la cultura de llegada mucho más que aquello que está registrado gráficamente en el papel.

Según Salgueiro (2014), los Estudios de la Traducción intentan dar cuenta del análisis de la producción de nuevos saberes comparatistas que repiensan las opciones de traducción resultantes de la mediación de lenguas y culturas puestas en contacto de forma inmediata e involuntaria, en conflicto con los poderes hegemónicos. En el caso de los estudios sobre África o la diáspora africana, la investigadora brasileña acentúa el papel decisivo de la traducción como forma de visibilidad/invisibilidad de las problemáticas identitarias, redefiniendo los significados de cultura y de identidad étnica a través de las discusiones entre la relación lengua $x$ poder:

Em várias obras traduzidas das literaturas de matriz africana para o Português do Brasil, pesquisadores apontam a tradução não como uma simples possível reprodução em outra língua de um texto original, mas sim como um processo que invariavelmente envolve atos deliberados de seleção, construção e -omissão. Sim, OMISSÃO, porque aquilo que não é traduzido em um contexto específico é sempre tão revelador quanto aquilo que é traduzido. Ou seja, silêncios e falhas em textos traduzidos- assim como a não tradução (ou a também chamada tradução zero) de textos inteiros - são aspectos fundamentais e reveladores da política de tradução em contextos culturais específicos. (Salgueiro, 2014: 76)

En nuestra investigación, analizaremos algunas discusiones sobre dos términos relacionados al campo semántico de la esclavitud africana en las Américas que vienen generando neologismos y adaptaciones en el portugués brasileño: escravo/a y mulata/o. Para pensarlos en una perspectiva de equivalencia español/portugués, utilizaremos las reflexiones de Arrojo (2007) que apuntan que el Texto de Llegada (TL) es una representación del Texto de Partida (TP), y lo cuán relevante es el acto interpretativo del traductor en ese proceso.

\section{La traducción intercultural y sus aportes a las teorías poscoloniales}

De acuerdo con Hall (2003a), las diferencias entre la cultura colonizadora y colonizada permanecen profundas, pero estas nunca operan de forma absolutamente binaria. El autor describe esa relación 
como un movimiento que parte de una concepción de diferencia para différance, según la concepción del término establecida por Jacques Derrida en 1972, lo que nos obliga a releer "os binarismos como formas de transculturação, de tradução cultural, destinadas a perturbar para sempre os binarismos culturais do tipo aqui/lá" (109). La différance impide que cualquier sistema se estabilice en una totalidad enteramente suturada. Las estrategias surgen de los vacíos y aporías que constituyen espacios potenciales de resistencia, intervención y traducción. El sujeto poscolonial se convierte en un producto de las diásporas, creado tanto por la migración como por los exilios involuntarios -como el caso de los esclavizados-, y necesita aprender a convivir con -como mínimo- dos identidades, a hablar dos lenguas culturales, a traducir y a negociar entre ellas, volviéndose de esta forma en un traductor cultural. En el caso específico de la traducción como transposición de textos, concordamos con Arrojo (1996) cuando afirma que pensar la différance "(...) tem permitido o abandono de perspectivas cientificistas e do desejo impossível de sistematizar e tornar asséptica a tarefa de traduzir" (62) al destacar el rol del traductor, pieza clave en la recepción de una obra literaria en el TL.

Bassnett (1999), investigadora de las relaciones entre literatura poscolonial y traducción intercultural, afirma que la traducción no ocurre apartadamente, sino en un continuo. No como un acto aislado, sino como parte de un proceso de transferencia intercultural. El traductor pasa entonces a ser un sujeto que participa de manera efectiva en la transformación y producción de significados, promoviendo una especie de doble traducción. De esa forma, podemos considerar la lengua materna y la lengua extranjera como complementarias y no antagónicas; aún más en el caso del portugués y del español, cuyos focos de traducción intercultural y de finalidad de los textos poscoloniales se acercan tanto por la proximidad lingüística como por las historias de conquista de tierras, colonización de pueblos y trata y esclavitud de seres humanos. Las lenguas en traducción se ocupan, además de la transcodificación lingüística, de la transmisión de elementos culturales.

Para el intelectual Boaventura de Sousa Santos (2010), la traducción cultural tiene como tarea recuperar las experiencias cognitivas perdidas por el epistemicidio masivo de las naciones del Norte que vigilan las fronteras de los saberes. Arrojo (1996) llama la atención a la proximidad de los procesos de colonización y de traducción. Las características aún defendidas por estudiosos de la traducción que se apoyan en una ética dominante y que se refieren a la transparencia y al respeto incondicional al "original" (poderoso, sagrado) se 
acercan a los rasgos también encontrados en la colonización como supremacía/superioridad del colonizador como pretexto para sobrepujar la cultura y la identidad del colonizado. El traductor, por lo tanto, debe estar consciente de la relevancia del texto que está traduciendo: "Imbuidas en diferentes culturas occidentales y no occidentales, esas experiencias usan no solo diferentes lenguas sino también diferentes categorías, universos simbólicos, y aspiraciones para una vida mejor" (Santos, 2010: 57)

Santos también defiende que la traducción actúa en los niveles lingüístico y cultural, y que, a través de la traducción intercultural, es posible identificar preocupaciones comunes, enfoques complementarios, y asimismo, contradicciones intratables. Por este motivo la traducción cultural será una tarea desafiante para filósofos, cientistas sociales, traductores e investigadores del siglo XXI. Por ejemplo, en las literaturas consideradas como de minorías, el aspecto intercultural de la traducción no solamente es necesario como indispensable, pues dichas literaturas están cargadas de factores políticos, culturales e ideológicos y tienen un fuerte papel social en sus comunidades. Si en el TP se reconoce la diversidad de experiencias, saberes y prácticas existentes en las comunidades culturales, su correcta interpretación y adecuada traducción resultará en un producto más conveniente y adecuado a su propuesta inicial. De acuerdo con Hall (2003a), si la traducción no considera características peculiares de las literaturas de minorías como el hibridismo cultural del sujeto diaspórico, su fragmentación y su constante duda entre asimilación o resistencia-, el TL se empobrecerá drásticamente y su sentido quedará comprometido. Por lo tanto, se hace necesaria la mediación textual por medio de miradas deconstruidas que conozcan y que respeten las culturas de llegada y partida, pudiendo, incluso, insertar el TL como referencia obligatoria en las discusiones intelectuales de variadas naciones. La producción literaria de la nigeriana Chimamanda Adichie es un gran ejemplo de los desafíos de traducir temas como el feminismo y la negritud en textos que vienen circulando por todo el mundo como pilares de una discusión sobre las violencias contra la mujer negra. Aunque sea una mujer negra africana escribiendo en inglés, la traducción que llega hasta la mujer negra brasileña que lee en portugués o a la mujer negra hispanoamericana que lee en español hace que estas reconozcan las mismas situaciones de prejuicios que viven aquellas a causa del género y del color de la piel. La traducción debe centrar su atención en temáticas tan sensibles como el racismo y en las especificidades de un discurso atravesado por el odio y los rencores de una situación de colonización y de opresión. 
En este sentido, Carrascosa (2017) señala que los textos literarios afrodiaspóricos han expresado narrativas, sonidos e imágenes que gestionan y reoperacionalizan los sentidos de viaje, pérdida y exilio con una función mnemónica de producir memoria social y consciencia de grupo en los procesos de invención e reinvención de la identidad negra. En la constitución del espacio-rizoma nombrado por Paul Gilroy (1993) como Atlántico Negro, la investigadora observa que su espaciada dirección privilegia la constitución de una zona de fuerzas en las cuales las producciones literarias se han confrontado con problemáticas y han representado sus subjetividades a partir de una serie de cuestiones y modos de acción. A partir de la propuesta de Spivak (1990), la traducción despunta en este espacio como tarea política de trabajo con el lenguaje, actuando como productora de identidad y subalternidad, además de ratificar su dimensión retórica como potencial agente generador de diseminación subversiva.

Al retomar la idea de que el texto traducido es un palimpsesto ${ }^{3}$, Arrojo (1996) afirma que el significado original no está fijo o estable y que depende del contexto en que originalmente ocurre. El texto se borra "em cada comunidade cultural e em cada época, para dar lugar a outra escritura (ou interpretação, ou leitura, ou tradução) do 'mesmo' texto" (23-24). La investigadora defiende la inevitabilidad de la interpretación y del sesgo inscritos en toda la traducción reafirmando el protagonismo del traductor, que reivindica su espacio huyendo de la inferioridad incómoda y de la transparencia imposible. A través de la concientización de una responsabilidad autoral por parte del traductor, este se vuelve componente esencial y participante activo en la creación de significados:

Em outras palavras, nossa tradução de qualquer texto, poético ou não, será fiel não ao texto "original", mas àquilo que consideramos ser o texto original, àquilo que consideramos constituí-lo, ou seja, à nossa interpretação do texto de partida, que será, como já sugerimos, sempre produto daquilo que somos, sentimos e pensamos. Além de ser fiel à leitura que fazemos do texto de partida, nossa tradução será fiel também à nossa própria concepção de tradução [...] [e] aos objetivos que se propõe (Arrojo, 2007: 44-45. Las cursivas son de la autora).

\footnotetext{
${ }^{3}$ Según la RAE, "manuscrito antiguo que conserva huellas de una escritura anterior borrada artificialmente". Acceso en 30.jun.2017
} 
De acuerdo con la autora no hay que detenerse en la fidelidad al TP, sino en un proyecto de traducción que debe ser conscientemente delimitado y respetado, teniendo en cuenta el público objetivo y la función de la traducción. En el caso de la literatura afrodescendiente, en Brasil los traductores tienen un nuevo reto en cuanto a las palabras "escravo/a" y "mulata/o", terminologías relacionadas a los contextos de esclavización africana en las Américas. Los movimientos negros brasileños (Geledés, Afronta, Blogueiras Negras, ABPN - Associação Brasileira de Pesquisadores Negros, por ejemplo) tienen una posición bastante clara en cuanto a la utilización de dichos términos: no los aceptan, ya que recuerdan incesantemente un pasado de traumas y violencias en el cual su situación social y racial era clasificada a partir de teorías occidentales racistas por hombres blancos que ocupaban el puesto de autoridad política e intelectual. Para Salgueiro (2014), las políticas de traducción pueden desempeñar un papel cultural discriminatorio cuyas consecuencias son la marginalización social, la pérdida de identidad y el trauma psicológico. En ese sentido, repensar el pasado en las Américas significa también revaluar patrones de uso lingüístico.

\section{Nuevos abordajes para la literatura afrodescendiente}

En Brasil, de la misma forma que en otras naciones latinoamericanas, la abolición de la esclavitud pasó por varias etapas hasta que un/a negro/a realmente no estuviera más en condición de esclavizado. A comienzos del siglo XIX se promulgó la ley que instituía la libertad de vientre, principio jurídico establecido por hombres blancos por el cual los hijos de las mujeres esclavizadas pasarían a tener derechos de individuos considerados libres. Más tarde, comenzaron las aboliciones efectivas. Actos que no pasaban de papeles firmados por los mismos hombres blancos en situación de poder: una libertad simbólica sin ningún tipo de proyecto político que realizara un cambio efectivo de las relaciones estructurales sociales. En el país, de acuerdo con Harkot-de-La-Taille y Santos (2012), la construcción discursiva sobre la esclavitud plantea la discusión sobre el término "escravo" como alguien que está en estado permanente, en una posición fija, sin cambios, en acomodación psicológica, revelando la naturalización de la condición cautiva y contribuyendo con su empleo para la amnistía de los actores del proceso histórico de deshumanización, despersonalización y de explotación identitaria del individuo en situación de esclavización. Sumándose los hechos de que la abolición fue firmada por una mujer -la princesa Isabeldurante la ausencia de la autoridad mayor -su padre, el Emperador D. Pedro II-, agregado al de la utilización de la voz pasiva en 
construcciones como "os negros foram libertados pela princesa Isabel", tenemos la liberación de esclavizados realizada por una mujer que, en un gesto casi que maternal, toma una decisión y firma un papel. Un acontecimiento político y social celebrado por los abolicionistas, pero con poca o casi ninguna relevancia para la población negra de la época y que se sigue enseñando en los currículos escolares brasileños como si, además de todas las apropiaciones y violencias contra los negros, aún permaneciera la idea de que ellos tendrían una deuda de gratitud por el gesto de "buena voluntad" de la princesa. Harkotde-La-Taille y Santos (2012) se valen de la hipótesis constructivista de la lengua, a partir de la cual la realidad es considerada una creación discursiva: “[...] uma notícia pontual e isolada será recebida como um acontecimento concreto, porém, quando o relatado é um acontecimento histórico socialmente ancorado, a hipótese construtivista supera a de descrição de uma realidade objetiva, como o tema da escravidão permite elucidar" (s/p).

Lo que se propone, de hecho, es un cambio en la utilización del término "escravo/a" por "escravizado/a", alguien que estaría en una situación que se puede cambiar. Esta alteración propone una modificación de la carga semántica que revela la denuncia del proceso de violencia subyacente a la pérdida de la identidad y que presupone la responsabilización y la presión hacia el blanco, el responsable por haber colocado al negro en una situación de esclavizado: "Já os usos contemporâneos que têm sido feitos do vocábulo escravizado para se referir à escravidão negra parecem ter como propósito resgatar o contexto e a relação histórico-social referente ao período escravocrata, evocando ressonâncias semânticas do pressuposto de responsabilização e de opressão pelo processo de escravidão" (Harkot-de-La-Taille \& Santos, 2012: s/p)

En el portugués brasileño Harkot-de-La-Taille \& Santos (2012) identificaron que apenas en el diccionario en línea Caldas Aulete el término "escravizado/a" está registrado como una entrada nueva cuyo significado lleva a "que se escravizou", "sofreu escravização", lo que demuestra una nueva visión de las relaciones histórico-sociales ocurridas en la época de la esclavitud. La RAE hasta ahora no cuenta con una entrada para "esclavizado/a". Sin embargo, aunque no esté registrado en el diccionario, es posible encontrarlo -todavía de manera un tanto tímida- en textos que tratan sobre la temática de la esclavitud ${ }^{4}$. Otro cambio significativo en la terminología del contexto

\footnotetext{
${ }^{4}$ El término "esclavizado" existe, pero como participio y no como sustantivo/sujeto. Buscando en la Internet, aisladamente existen algunos movimientos negros que están reivindicando la utilización de "esclavizado" como en el sitio de Cimarrones Comunicación Interétnica en Perú, cuyo objetivo es rescatar, revalorar y difundir la cultura afroperuana. Véase López Schmidt (2005).
} 
de esclavitud se refiere a las palabras "mulato/a", en especial a la versión femenina del término. Los movimientos negros brasileños rechazan la utilización de la palabra por dos motivos: 1) lingüístico -derivación de "mulus", del latín, actualizado por "mula", el animal que surge de la cópula de dos razas distintas -el asno y la yegua, que, en el siglo XVI, derivó en la América hispánica para "mulato" como una analogía con el carácter mestizo del animal; y 2) cultural -la falsa impresión de democracia racial que hay en el país, agregado a la representación de la mujer negra o mestiza como un cuerpo hipersexualizado.

En 1933 Gilberto Freyre publicó la obra Casa Grande e Senzala, en la que el antropólogo apostó por la ascensión social del mulato, caracterizándolo como el fenotipo brasileño, resultado de las relaciones amigables y relajadas entre blancos y negros, al contrario de los EE.UU, donde los negros eran segregados. La sensación de democracia racial brasileña se deconstruye, sin embargo, en la medida en que se discute cómo la población se volvió mestiza -a través de las violencias practicadas por hombres blancos, señores de esclavizados, a las mujeres negras esclavizadas, y de las políticas de blanqueamiento insertas por gobiernos que valoraban la estética blanca. El discurso de que el mulato es la expresión de la brasilidad que se transmite al elogiar el mestizaje se deshace, pues la autorización para uniones extrarraciales tenían como objetivo el "mejoramiento" de la raza. A partir de nuevos estudios teóricos, se sostiene que el mito de la democracia racial promueve la perpetuación de la hegemonía ideológica blanca en el poder y le imposibilita al negro la liberación de su condición de subciudadano:

Aproximadamente duas décadas mais tarde, depois da teoria da cordialidade de Gilberto Freyre, uma nova geração de cientistas sociais, ao estudar a discriminação racial no Brasil, acumulou evidências de que os brancos foram preconceituosos e os negros informalmente segregados. Tais cientistas, denominados revisionistas, perceberam que as possibilidades de mobilidade social foram limitadas ao negros, o que os levou a ocupar a base da pirâmide social brasileira e, sempre que competiam com brancos, eram discriminados. Os revisionistas mais importantes como Florestan Fernandes, Roger Bastide, Thales de Azevedo, Octavio Ianni, Fernando Henrique Cardoso e Guerreiro Ramos foram acusados, a princípio, de inventar um problema racial que não existia no Brasil mas, com o tempo, 
suas teorias foram ganhando adeptos e a teoria da cordialidade foi ultrapassada. 0 que era uma realidade na geração de Freyre, tornou-se um mito arruinado e desacreditado nas gerações seguintes (Silva, 2007: 166-167).

El ícono de la democracia racial es la figura de la "mulata", en la cual hay una fuerte imposición de su rol sexual, hecho registrado por Freyre (1933) al discutir la sustitución de las mujeres blancas -en número escaso durante la colonización- por mujeres indígenas y negras -en mayor número y consideradas "fáciles" al cambiar relaciones sexuales por favores, regalos y status, negando el papel patriarcal y dominador del hombre blanco-. En Casa Grande e Senzala, se describe a la mujer negra como contadora de historias y gran cocinera: una figura importante en la niñez. Ya en la juventud, los recuerdos son de la mulata: aquella que inicia los hombres en los caminos del amor. ${ }^{5}$ Lo que se discute es que, ante la imposibilidad de que los hombres blancos asumieran una relación con una mujer negra -cargada de categorías negativas a raíz de la esclavitud-, fue necesario "crear" una figura que estuviera libre de la discriminación racial, con características mayormente sexuales, que ocupó un nuevo papel social en cuanto a las negras explotadas. La mulata representa, por lo tanto, la negación de la mujer negra y su "creación" surge del prejuicio y del machismo de la sociedad de la época. ${ }^{6}$ Actualmente, los movimientos negros, en especial los organizados por las mujeres negras, no aceptan el término "mulata" por todas las implicaciones que carga el vocablo.

Estas discusiones llegaron a los medios. En el 2015 la lectora Marcela Pedrosa escribió a Sérgio Rodrigues, responsable de la columna "Sobre Palavras", de la revista Veja -una de las publicaciones más reaccionarias del país, con orientación ideológica de extrema derecha- preguntándole al columnista si consideraba una ofensa racista la utilización de la palabra "mulata". En su respuesta el investigador explicó el origen etimológico de la palabra (ya comentada en esta investigación) y, por fin, opinó sobre la posibilidad de ser o no racista:

\footnotetext{
${ }^{5}$ En la literatura brasileña se puede citar Jorge Amado como el gran representante de la construcción estereotipada de la mulata sensual como caracterización de la cultura del país.

${ }^{6}$ Una búsqueda rápida en el Google Brasil por la palabra "mulata" resultó en imágenes en la pantalla con mujeres mestizas de biquini, casi desnudas y en posiciones sensuales (Una búsqueda realizada el 9 de marzo de 2017).
} 
O tom depreciativo da associação original é indiscutível e facilmente explicável pelo racismo escancarado de uma época escravocrata. 0 que cabe discutir é se vale a pena condenar o vocábulo por causa disso.

Fazê-lo significa manter artificialmente vivo na língua de hoje um parentesco praticamente esquecido, além de ignorar os novos sentidos -alguns deles francamente positivos, como o da exaltação da miscigenação- que foram se colando com o passar do tempo ao termo "mulato(a)". (Rodrigues, 2017, s/p)

Rodrigues argumenta que la exaltación del mestizaje fue "francamente positiva" y que la condenación del vocablo significaría mantener un sentido prácticamente olvidado. Debemos recordar que dicha opinión es de un hombre blanco que habla desde su lugar como tal, es decir, desde un lugar privilegiado que tiene poco o ningún contacto con los movimientos negros. Para contestar a esta pregunta, lo mínimo que podría haber hecho el escritor sería contactar a alguien -negro- que siente los prejuicios por ser afrodescendiente, y preguntarle a una mujer negra cómo se siente cuando la llaman mulata, un registro claramente direccionado a la hipersexualización del cuerpo negro. Es esa la crítica que se hace: los estudiosos de la lengua portuguesa en Brasil no escuchan a los movimientos negros en cuanto a sus reivindicaciones, manteniendo las situaciones de poder a través de la lengua: "Nesse aspecto, a escravidão, enquanto atividade migratória forçada com fins de mercado visando ao lucro de terceiros, se encaixa claramente nesse quadro teórico que joga luz sobre as reflexões acerca do processo tradutório" (Salgueiro, 2014: 77).

Por lo tanto, contestar a este tipo de pregunta -si es o no racista utilizar el término "mulata" - en una publicación de giro nacional sin preguntarle a alguien negro cómo se siente o investigar dicha reivindicación en los blogs y/o publicaciones de páginas de organizaciones negras, es una forma de colonización de la terminología desde una perspectiva de hombre blanco que no ve problema alguno en la utilización del término, ya que no consigue ponerse en el lugar del otro para mínimamente repensar su afirmación basada apenas en los estudios lingüísticos convencionales, no aplicados a los nuevos empleos postulados por los (hasta entonces) silenciados.

Por otra parte, nuestra investigación encontró en el sitio Geledés - Instituto da Mulher Negra -que discute temáticas raciales y 
cuestiones de género- un poema de $\operatorname{cordel}^{7}$ de autoría de Jarid Arraes sobre la utilización del término "mulata". Tenemos aquí la visión de una mujer negra hablando desde su lugar y reivindicando cómo le gustaría ser llamada:

"Não me chame de mulata"

Eu começo este cordel

Recorrendo ao dicionário

Pois o tal livro reflete

Um saber reacionário

Já que o significado

Do verbete ali mostrado

É antigo e ordinário.

$[\ldots]$

Essa palavra "mulata"

Ela não me representa

Não sou cria de jumento

Nem de burro sou rebenta

Eu sou filha duma gente

Corajosa e imponente

Com história opulenta.

[...]

Não me chame de mulata

Eu sou uma negra orgulhosa

Não me chame de morena

Eu sou preta vigorosa

Tenho gana para lutar

Para todos ensinar

Sempre bem esperançosa.

Para Hall (2003a), las palabras son "multimoduladas" y siempre cargan ecos de otros significados que ponen en movimiento, a pesar de nuestros mejores esfuerzos para limitar el significado: "Tudo o que dizemos tem um 'antes' e um 'depois' -uma 'margem' na qual outras pessoas possam escrever. 0 significado é inerentemente instável: ele procura o fechamento (a identidade), mas ele é constantemente perturbado (pela diferença). Ele está constantemente escapulindo de nós" (41). El término "mulata" se encaja perfectamente en la definición de Hall, pues no utilizarlo significa respetar la voluntad de

\footnotetext{
7 "Poesía de cordel" es un género brasileño (de origen europeo) de gran popularidad, desarrollado en el espacio geográfico del sertão, que se caracteriza por su popularidad en versos cantados o impresos en folletos baratos colgados en pliegos de cordel puestos en venta en tendederos de cuerda.
} 
las mujeres negras que ven el él una forma de racismo y depreciación constantes desde la época de la esclavitud. En español, todavía no encontramos un texto teórico que discutiera la utilización del término en el contexto hispánico. Para que el traductor sepa si debe traducir "mulata" del español al portugués por "mestiça" o "negra" habrá que comprender más allá del TP e interpretar cuál es el sentido que quiso darle el autor.

Spivak (1990) define la traducción como transmisión de textos literarios y culturales a través de una forma -otra- de imaginar culturas de manera más comprensiva y más responsable como estímulo para un (re)pensarnos a nosotros mismos a partir de la mirada de los pueblos emergentes. Aseverando las afirmaciones de Hall, Bassnet y Santos, para la intelectual india los desafíos del traductor no se resumen en las dificultades específicas relativas a la transposición de los idiomas, sino que se amplían en la transmisión de las marcas culturales peculiares de determinadas regiones de la cultura de partida a la cultura de llegada, con su complejidad de enredos y personajes, y asimismo, en el fuerte papel social de este tipo de literatura. Hacer oídos sordos a la voz de aquellos que siempre estuvieron en situación de subalternidad y seguir utilizando los términos "escravo/a" y "mulato/a" es irrespetar sus voces y seguir manteniendo la opresión y el silenciamiento de los individuos negros.

\section{Campos de aplicación en Brasil}

Salgueiro (2014), en Traduzir a negritude: desafio para os estudos de tradução na contemporaneidade cuestiona: ¿cuál el papel de la traducción en los procesos de construcción identitaria colonial y poscolonial? ¿Estamos conscientes del sesgo político de dichas acciones traductorias? Para la investigadora:

Traduzir, com todas as tensões envolvidas, é hoje atividade vista de forma absolutamente diversa do que há alguns anos atrás. Os conflitos globais, as reflexões teóricas que forçosamente foram ocorrendo fizeram dessa reescrita algo potente e possante no mundo contemporâneo. No que tange aos textos afrodescendentes, inseridos em toda a dinâmica dessa discussão nos dias de hoje não podia ser diferente (Salgueiro, 2014: 89)

En este aspecto, llamamos la atención a dos términos que vienen resignificándose en los últimos años: "escravo" y "mulata", en ambos 
géneros. En Brasil, ejemplificaremos con la problemática de que los traductores de obras hispánicas que tratan de temáticas afro en el género novela son blancos (Silva, 2016), y por lo tanto, en estos textos traducidos, no se percibe un comprometimiento con las reivindicaciones de los movimientos negros. Plantearemos como ejemplo a Joana Angélica D’Avila Mello, la traductora al portugués brasileño de Perro Viejo (2006), de la cubana Teresa Cárdenas. Ella nació en Sergipe en 1941, se graduó en Letras Neolatinas y en Periodismo, y tuvo una circulación importante entre las editoriales. Responsable de la traducción de obras de Mario Benedetti y Mario Vargas Llosa y por su formación en lenguas traductora del francés e italiano. En Perro Viejo el término "esclavo" aparece varias veces en la obra, que trata de un anciano que rememora su vida de esclavizado con todas las violencias, los silenciamientos y las prohibiciones acometidas. La traductora optó por utilizar, en portugués, "escravo":

TP: Con el toque mañanero de la campana, los esclavos inclinaban la cabeza ante el Señor que colgaba desnudo en una cruz a un costado del barracón, cerca del bebedero de los cerdos (Cárdenas, 2006: 16. La cursivas es nuestra)

TL: Com o toque madrugador do sino, os escravos inclinavam a cabeça ante o Senhor que pendia nu de uma cruz ao lado do barracão, perto do bebedouro dos porcos (Cárdenas, 2010: 21. Traducción de Joana Angélica D' Avila Melo. La cursiva es nuestra).

TP: Un esclavo nunca podría enderezarse delante de ellos y mucho menos mirarles a los ojos. (Cárdenas, 2006: 17. La cursiva es nuestra).

TL: Um escravo nunca poderia ficar ereto diante deles e muito menos fitá-los nos olhos. (Cárdenas, 2010: 22. Traducción de Joana Angélica D’Avila Melo. La cursiva es nuestra)

Se trata de una traductora con larga experiencia en práctica de traducción y que es elogiada por su capacidad de mantenerse en el texto original, el modelo a seguir. Recluida y discreta es imposible encontrar una imagen suya en la internet-, Joana Angélica es considerada una traductora brillante (responsable por traducir al portugués brasileño, entre otros, La esposa joven, de Alessandro Barrico; El cementerio de Praga, de Umberto Eco; y Las nuevas enfermedades del alma, de Julia Kristeva). Sin adentrar 
en un juicio sobre la traducción de la obra Perro Viejo, se percibe la opción de mantener el término como siempre ha sido utilizado: o por desconsiderar los cambios semánticos y las reivindicaciones de personas negras, o probablemente por respetarlos, pero optando por no dar eco a las demandas y mantener una traducción con los equivalentes recurrentes.

Cabe destacar un contrapunto a esta posición a través de una nueva propuesta semántica de utilización del término. En Brasil, en el año de 2017, se produjo en la emisora Band la serie televisiva Era uma vez uma história ${ }^{8}$ (Érase una vez una historia) en la que la historiadora Lilia Schwarcz ${ }^{9}$, junto al actor Dan Stulbach, presentó una revisión de la historia brasileña del 1806 al 1899. Dividida en cuatro capítulos, la propuesta fue unir dramaturgía y entretenimiento con relevancia histórica. En la atracción televisiva, los presentadores actúan como testigos y narradores de hechos que determinarían los rumbos políticos, económicos y culturales del país, recordando de forma crítica algunas situaciones (como la llegada de la familia real a Brasil) y también denunciando exploraciones (como la de los negros esclavizados), razonando que la situación actual de pobreza de la población negra en Brasil se mantiene así por la falta de políticas de acogimiento tras la abolición. En varios momentos del programa, tanto Lilia como el narrador utilizan la palabra "escravizado/s". Dan Stulbach, que representa un personaje que debate los hechos con Lilia, la profesora, es corregido por ella cuando profiere "escravo" (un ejemplo de ello ocurre en el episodio IV, parte 1, a los 4'10).

En cuanto al término "mulato/a", en especial en la versión femenina, la discusión se vuelve más enrevesada. Conforme hemos discutido anteriormente, se percibe que las mujeres negras requieren ser nombradas como negras, en un acto de autoafirmación étnica. En cuanto a los estudiosos de la lengua-blancos-, afirmar que no utilizar el término por recelo de borrar la historia de la lengua sigue la línea de colonización y autoridad sobre el lenguaje que los movimientos negros reivindican a través de la manutención de una situación de poder sobre la palabra. Sin embargo, en este caso, nos preguntamos: ¿cuál serían las opciones para el traductor? ¿Cómo portarse con la

\footnotetext{
${ }^{8}$ Los episodios están disponibles integralmente en https://www.youtube.com/ watch?v=W1koQDr2HiE

${ }^{9}$ Lilia Moritz Schwarcz es profesora de la Facultad de Filosofía, Letras y Ciencias Humanas de la Universidad de São Paulo (USP). Historiadora y antropóloga, publicó varias obras relacionadas con la presencia de negros esclavizados en Brasil: Retrato em branco e negro: jornais, escravos e cidadãos em São Paulo no fim do século XIX (1987), Nem preto nem branco, muito pelo contrário (2012) y Brasil: uma biografia (2015), entre otras reflexiones históricas sobre el Brasil colonial.
} 
traducción de textos históricos publicados en siglos pasados? ¿Con los históricos publicados en este siglo? Y en el caso de la traducción cultural, ¿cómo proceder con la traducción de "mulata" del español, término ampliamente defendido por Manuel Zapata Olivella, intelectual negro colombiano, y despojado de la hipersexualidad de la propuesta de Freyre en Brasil? Como se puede observar, las discusiones son todavía incipientes, pero deben salir a la luz para el perfeccionamiento del debate sobre el lenguaje afrodiaspórico observando el

[...] conjunto de traços que derivaram, dentre tantos outros, da força cultural afrodiaspórica, são fundamentais ao exercício político da tradução de seus textos literários, mesmo porque eles estão aí intimamente imbricados, fazendo parte dessa matriz de produção. Portanto, na instância da linguagem, como uma das faces da dobradiça da tarefa política da tradução, é preciso acioná-los. Preciso porque necessário e preciso porque deve haver uma precisão estético-ética nessa empreitada, coerente com a funçãotradutor do Atlântico Negro, qual seja: intensificação dos rastros da cultura afrodiaspórica no sentido de que sua força conecte os pontos ainda dispersos desse mapa imaginário e geste novas geografias menos geopolíticas e mais "geo-éticas". (Carrascosa, 2017: 72)

Se suma a la discusión el hecho de que en Brasil la gran mayoría de los traductores no son negros o no se presentan como tal ${ }^{10}$, lo que instiga aún más la polémica sobre las temáticas afrodiaspóricas en el país.

\section{Consideraciones finales}

Retomando la pregunta inicial de Spivak (2010) al cuestionar si realmente el subalterno está en una posición en la que puede hablar y ser escuchado, destacamos que, como mínimo, debemos ejercitar nuestra capacidad de comprensión e interpretación de los sujetos silenciados. El traductor, en su trabajo de traducción interlingüística e intercultural, es parte fundamental de ese proceso, definiendo si interferirá más o menos en el texto al conocer más

\footnotetext{
${ }^{10}$ Como se puede confirmar en Silva-Reis, D. (2015) y en la entrevista con Amaury Williams de Castro, que aborda las reflexiones sobre ser traductor e intérprete actuando en espacios mayoritariamente de circulación de blancos (hoteles de lujo, centros de convenciones, etc.).
} 
o menos sobre el tema tratado. Arrojo (1996) llama este proceso "pérdida de la inocencia" en los estudios de la traducción, cuando ocurre el reconocimiento por parte del traductor de que no hay una ética disociada de intereses a los que inevitablemente sirve. Él sabe que "hace alguna cosa" y tiene consciencia de ese hacer y sus consecuencias. Si el traductor no interfiere, no toma partido y mantiene el texto aséptico -como es el caso de la traductora Joana Angélica en Perro Viejo-, se configura también en una toma de posición. En cuanto a los traductores: "Quanto mais conscientes estiverem dessa realidade e do papel que exercem sobre e a partir dela, menos hipócrita e menos ingênua será a intervenção linguística, política, cultural e social que inescapavelmente exercem (Arrojo, 1996: 64).

Traducir se configura, por lo tanto, en un acto de resistencia contra posiciones dominantes que explotan e interfieren en las comunidades culturales. La traducción bajo la óptica de los Estudios Culturales es un factor imprescindible para la diseminación de los saberes por el mundo, a través de expresiones como la canción, la literatura, el cine y el pensamiento intelectual, en especial para las naciones hasta entonces silenciadas y marginalizadas y que hoy consiguen hacer correr su voz debido a las facilidades tecnológicas de divulgación de sus productos a nivel mundial. El traductor es el vocero de las comunidades silenciadas, y al ser consciente de ello, se vuelve un mediador legitimado para la transmisión cultural entre naciones. En el caso de la traducción de temática afrodescendiente, se hace más que necesaria la integración de traductores negros participantes de estas nuevas realidades, que puedan compartir desde sus vivencias las opciones de traducción más adecuadas a sus experiencias híbridas.

\section{Bibliografía}

Arrojo, R. (2007) Oficina de tradução: a teoria na prática. 5.ed. São Paulo: Ática.

(1996). "Os estudos da tradução na pós-modernidade, o reconhecimento da diferença e a perda de inocência", Cadernos de tradução, vol. I, no 1, pp. 53-69: https://periodicos.ufsc.br/ index.php/traducao/article/view/5064/4567 [Consultado el 28 de febrero de 2017].

Arraes, J. (2015). "Não me chame de mulata", Geledés Instituto da Mulher Negra: http://www.geledes.org.br/nao-chame-de-mulata/\#gs. kbIBPnU [Consultado el 9 de marzo de 2017]. 
Bassnet, S. (1999). Post-colonial translation: theory and practice. Brighton: Routledge.

Cárdenas, Teresa. (2006). Perro viejo. La Habana: Fondo Editorial Casa de las Américas.

- Cachorro Velho. Rio de Janeiro: Pallas. (Traducción de Joana Angélica D'Ávila Melo).

Carrascosa, D. (2017). “Traduzindo no Atlântico Negro. Por uma práxis teórico-política de tradução entre literaturas afrodiaspóricas”. En Carrascosa, D. (ed.) Traduzindo no Atlântico Negro: cartas náuticas afrodiaspóricas para travessias literárias. Salvador: Ogum's Toques Negros, pp. 63-75.

Freyre, Gilberto. (1933). Casa Grande \& Senzala. Formação da família brasileira sob o regime de economia patriarcal. Rio de Janeiro: Maia \& Schmidt.

Gilroy, Paul. (1993). The black Atlantic: modernity and double consciousness. Cambridge, Mass: Harvard Univ. Press.

Hall, S. (2003 ). A identidade cultural na pós-modernidade. Rio de Janeiro: DP\&A. (Traducción de Tomaz Tadeu da Silva y Guaracira Lopes Louro).

(2003b). Da diáspora. Identidades e Mediações Culturais. Organização de Liv Sovik. Belo Horizonte: Editora UFMG; Brasília: Representação da UNESCO no Brasil. (Traducción de Adelaine La Guardia Resende et al.)

Harkot-de-la-taille, E. \& Santos, A.R. (2012) "Sobre escravos e escravizados: percursos discursivos da conquista da liberdade", Anais do III Simpósio Nacional Discurso, Identidade e Sociedade. Desafios e percursos na contemporaneidade: http://www.iel.unicamp.br/sidis/anais/pdf/ HARKOT_DE_LA_TAILLE_ELIZABETH.pdf [Consultado el 8 de marzo de 2017].

Rodrigues, S. (2017). 'Mulata' veio de mula? Isso torna a palavra racista?: http://veja.abril.com.br/blog/sobre-palavras/8216-mulata8217-veio-de-8216-mula-8217-isso-torna-a-palavra-racista [Consultado el 8 de marzo de 2017].

Salgueiro, M. A. A. (2014). "Traduzir a negritude: desafio para os estudos da tradução na contemporaneidade", Cadernos de Letras da UFF, no 48, Rio de Janeiro, pp. 73-90.

Santos, B. S. (2009). "Epistemologias do Sul". En Meneses, M. P. (Ed.). Coimbra: Edições Almedina S/A. (2010). Descolonizar el saber, reinventar el poder (José Luis Exceni R., José Guadalupe Gandarilla Salgado, Carlos Morales de Setién y Carlos Lema, trads) Montevideo: Ediciones Trilce.

Silva, L. R. (2016). "A voz do protagonista afrodescendente em romances históricos hispano-americanos: invisibilidade do texto original e algumas (poucas) obras traduzidas no Brasil", Cadernos de Literatura em Tradução, no 16, São Paulo, pp. 73-88: http://www. 
revistas.usp.br/clt/article/view/115272 [Consultado el 30 de junio de 2017].

. (2007). "Verbete Democracia Racial". En Bernd, Z. (Ed). Dicionário de Figuras e Mitos Literários das Américas - DFMLA. Porto Alegre: Tomo Editorial/Editora da UFRGS, pp. 165-171.

Spivak, G. C. (2003). “The Post-Colonial Critique”. En Harasym, S. (Ed.). The Post-Colonial Critique. Interviews, Strategies, Dialogues. Nova Iorque: Routledge.

\& Giraldo, S. (2003). “PPuede hablar el subalterno?”, Revista Colombiana de Antropología, no 39, Bogotá, Instituto Colombiano de Antropología e Historia, pp. 297-364: http://www.redalyc. org/pdf/105018181010 [Consultado el 25 de febrero de 2017]. 
